Check for updates

Cite this: RSC Adv., 2020, 10, 39033

Received 27th August 2020

Accepted 13th October 2020

DOI: $10.1039 /$ dOra07677e

rsc.li/rsc-advances

\section{Circular linkage of intramolecular multi-hydrogen bonding frameworks through nucleophilic substitutions of $\beta$-dicarbonyls onto cyanuric chloride and subsequent tautomerisation $\dagger$}

\author{
Ayano Awatani and Masaaki Suzuki iD *
}

\begin{abstract}
Nucleophilic substitution reactions of cyanuric chloride with a series of $\beta$-dicarbonyls give triply $\beta$ dicarbonyl-embedded 1,3,5-triazines. Their subsequent but spontaneous tautomeric transformation leads to circularly linked, intramolecular, multi-hydrogen bonding networks. Their structural elucidation by X-ray crystallography showed elongated double bonds and shortened single bonds. This is likely due to a resonance hybrid formed via tautomerisation and simultaneous proton transfer.
\end{abstract}

Intramolecular hydrogen bonding contributes to various chemical phenomena, such as the stabilisation of molecules ${ }^{1}$ and/or three-dimensional arrangements of molecular frameworks. ${ }^{2}$ Normally, hydrogen bonding units are formed between heteroatomic functionalities, including alcohols, ketones, amines, imines, and halogens. When these are incorporated into a conjugated network, proton delivery alongside resonance, i.e. excited-state intramolecular proton transfer (ESIPT), can occur. ${ }^{3}$ Among numerous examples, an excited-state doubleproton transfer (EDIPT) was reported by Chou et al., ${ }^{4 a, b}$ where an ingenious arrangement of serial hydrogen bonding occurred in 1,8-dihydroxy-2-naphthaldehyde (DHNA, Chart 1a) that promoted a remarkably large Stokes shift. Adachi et al. ${ }^{4 c}$ also developed a triquinolonobenzene (TQB) system that could potentially exhibit a characteristic triple-ESIPT; however, TQB could not cause the third ESIPT (Chart 1b). This was likely due to high barriers to breaking the inherent stability of the Clar structure and amine-ketone skeletons of TQB.

Aromaticity is one of the best properties that stabilises molecules and is achieved via the delocalisation of $\pi$-electrons, as long as they satisfy Hückel's rule. Whenever possible, organic compounds will adopt aromatic skeletons, including nonclassical Möbius systems, that are suitable for designated factors by undergoing protonation/deprotonation, ${ }^{5}$ macrocyclic distortion, ${ }^{6}$ or many other perturbations. There are several other mechanisms besides aromaticity that provide stability. One example is the amide-iminol tautomerism ${ }^{7}$ of cyanuric acid, whose original 2,4,6-triol form undergoes tautomerization

Graduate School of Natural Science and Technology, Shimane University, 1060 Nishikawatsu-cho, Matsue, Shimane 690-8504, Japan. E-mail: m-suzuki@riko. shimane-u.ac.jp

$\dagger$ Electronic supplementary information (ESI) available. CCDC 2014517-2014520. For ESI and crystallographic data in CIF or other electronic format see DOI: 10.1039/d0ra07677e to give isocyanuric acid, which adopts a 2,4,6-trione structure. The original structure is aromatic due to the 1,3,5-triazine core; however, an amide is more stable than an iminol. Therefore, both tautomers contribute to the cyanuric acid structure. These observations inspired us to create an organic molecular scaffold that could overcome aromatic stabilisation by other mechanisms.

An intramolecular hydrogen bonding framework would serve as a nice platform to realise our aforementioned idea, and we focused on the tautomerism of cyanuric acid. This process generated $\mathrm{NH}$ protons that could serve as hydrogen-bonding donors. When such a hydrogen-bonding donor is surrounded (a)

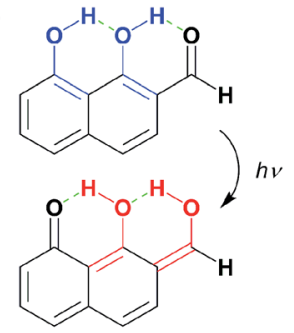

(c)

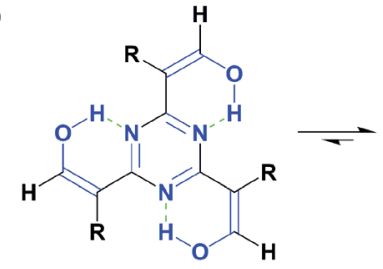

(b)

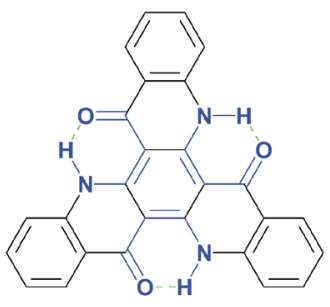<smiles>[R]C(=O)/C=C1\C([R])C(=O)N(C)C(=C([R])C(=O)O)N1C</smiles>

Chart 1 Selected examples demonstrating intramolecular proton transfers: (a) 1,8-dihydroxy-2-naphthaldehyde (DHNA) and its excitedstate double proton transfer (ESDPT), (b) triquinolonobenzene, and (c) tautomerism of 2,4,6-tris( $\beta$-monocarbonyl)-1,3,5-triazine (TMCT). 
by acceptors, an intramolecular, multi-hydrogen bonding entity can be formed. A pioneering work that attempted to fabricate such a bonding entity focused on resonance-assisted hydrogen bonding (RAHB) systems. ${ }^{8}$ Liebscher and co-workers ${ }^{8 b}$ synthesised 2,4,6-tris( $\beta$-monocarbonyl)-1,3,5-triazine (TMCT) by the stepwise extension of the benzyl positions of 2,4,6-trialkyl1,3,5-triazine and demonstrated the subsequent tautomerism into the corresponding 2,4,6-triylidene structures (Chart 1c). However, there were evident contributions from aromatic 1,3,5triazine forms based on the broadened $\mathrm{NH}$ signals in their proton nuclear magnetic resonance $\left({ }^{1} \mathrm{H} \mathrm{NMR}\right)$ spectra. The design of our target molecule (B, Chart 2 ) began with cyanuric chloride (1) undergoing nucleophilic substitution with three $\beta$ dicarbonyls (i), which led to the desired triply conjugated 1,3,5triazine derivative (A). Automatic tautomerization (ii) formed a circular array of multi-hydrogen bonding interactions amongst the molecular periphery to give $\mathbf{B} .{ }^{9}$ As a result, the acceptors would be connected to the core by double bonds. Such a macrocyclic arrangement of multidentate RAHB arrays is the major difference between our compound and the reported TMCT systems, which possess independent monodentate RAHB sites. ${ }^{8 b}$ Compound $\mathbf{B}$ has been already reported, but the characterisation was limited by several, insufficient spectroscopic predictions (the NMR spectrum only showed its alkoxy protons). ${ }^{10}$ We predicted that proton transfer from the nitrogen atoms to the adjacent oxygen atoms (iii) would spontaneously occur without any stimuli, such as photoirradiation, owing to the decreased energy barrier that resulted from the directly conjugated hydrogen-bonding donor-acceptor assembly. A possible resonance form (C) was also depicted. The final goal of this project is to create highly delocalised, electronic platforms comparable to conventional carbon-rich materials.

Several $\beta$-dicarbonyls (2) were tested for their performance in nucleophilic substitution reactions with 1., ${ }^{\mathbf{9 1 1}}$ Diisopropylethylamine (DIEA) was chosen as the organic, non-nucleophilic base because its moderate boiling point would enable easy removal under reduced pressure (Scheme 1). DIEA and 2 were used in excess to avoid tedious chromatographic separation of the highly polar mono- and di-conjugates. The reaction employing Meldrum's acid (2a) gave a pale-yellow crystalline solid that was identified as $\mathbf{3 a}$.

The ${ }^{1} \mathrm{H}$ NMR spectrum of 3a (Fig. S1, ESI $\dagger$ ) exhibited a pair of signals in the aliphatic region at $1.77 \mathrm{ppm}$ and in a significantly downfield region at $\mathbf{1 5 . 1 3} \mathrm{ppm}$. These likely represented the methyl $\left(\mathrm{H}^{\mathrm{b}}\right)$ and $\mathrm{NH}\left(\mathrm{H}^{\mathrm{a}}\right)$ protons, respectively, which reflects
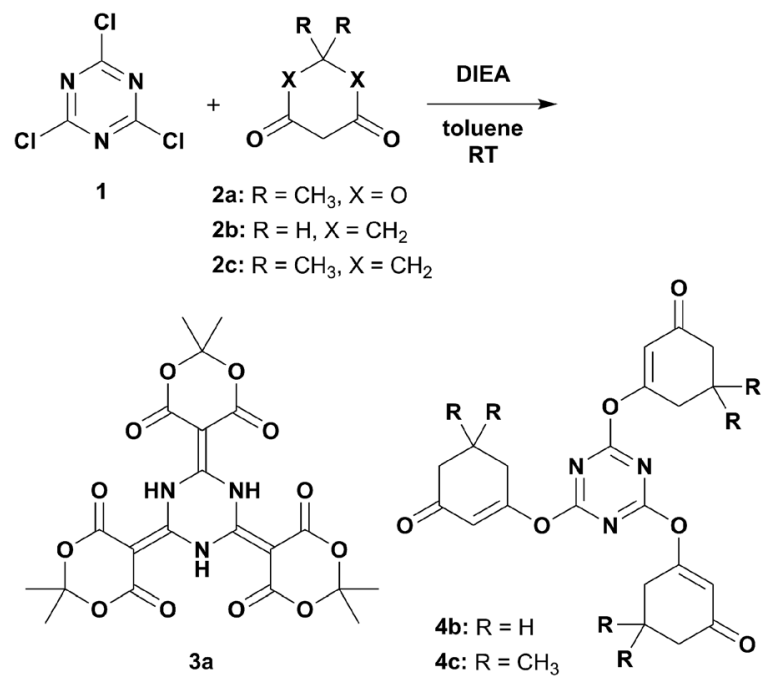

Scheme 1 Nucleophilic substitution reactions of $\beta$-dicarbonyls onto cyanuric acid with diisopropylethylamine in toluene at room temperature.

the highly symmetric structure of 3a. The deshielded NH signal suggests that the expected $\mathrm{O} \cdots(\mathrm{N}) \mathrm{H} \cdots \mathrm{O}$ bidentate hydrogen bonding was occurring. This is supported by the signals of $\mathrm{O} \cdots$ (N)H monodentate hydrogen bonding in not only TMCT systems, which exhibited their $\mathrm{NH}$ signals at $13.40-13.90 \mathrm{ppm},{ }^{8 a}$ but also those in related mono-conjugates at ca.13.50 ppm. ${ }^{11 d}$ The ${ }^{13} \mathrm{C}$ NMR spectrum of 3a (Fig. S2 $\dagger$ ) displays two aliphatic signals $\left(\mathrm{C}^{4}\right.$ and $\left.\mathrm{C}^{5}\right)$ at 27.08 and $79.03 \mathrm{ppm}$, respectively, as well as two olefinic $\left(\mathrm{C}^{1}\right.$ and $\left.\mathrm{C}^{4}\right)$ signals at 105.27 and $149.76 \mathrm{ppm}$, respectively. A carbonyl $\left(\mathrm{C}^{3}\right)$ signal also appeared at $163.45 \mathrm{ppm}$. These signals further affirmed that the desired structure was successfully fabricated.

The final structures of 3a were elucidated by X-ray diffraction analysis (Fig. 1a and $\mathrm{S} 21 \dagger$ ), which revealed spectroscopic assignments that agreed with the expected molecular design. The N-O1 distances were 2.623(2)-2.680(3) A, which indicated that certain hydrogen bonding interactions existed. The $\mathrm{N}-\mathrm{C} 1$, C1-C2, C2-C3, and C3-O1 distances were 1.350(3)-1.369(4), 1.387(4)-1.392(3), 1.445(4)-1.464(5), and 1.209(3)-1.218(4) ̊, respectively, which were estimated to be intermediate lengths of the alternating single and double $\mathrm{C}-\mathrm{C}, \mathrm{C}-\mathrm{N}$, and $\mathrm{C}-\mathrm{O}$ bonds. ${ }^{12}$

On the other hand, when 1,3-cyclohexanedione (2b) was used as the $\beta$-dicarbonyl, the $O$-linked product $\mathbf{4 b}$ was obtained (Scheme 1). The ${ }^{1} \mathrm{H}$ NMR spectrum of $\mathbf{4 b}$ (Fig. S9†) provided four

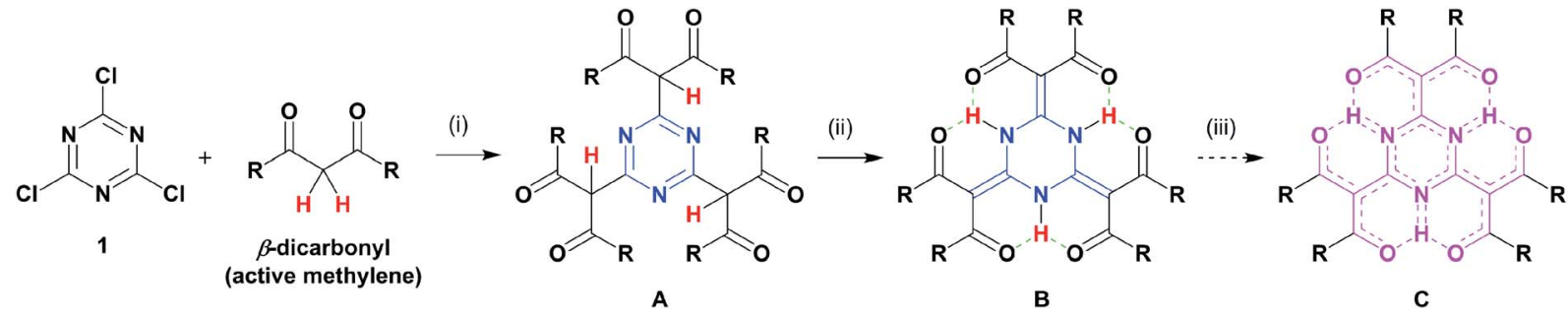

Chart 2 Concept of this work: (i) nucleophilic substitution, (ii) tautomerism, and (iii) resonance. 
(a)

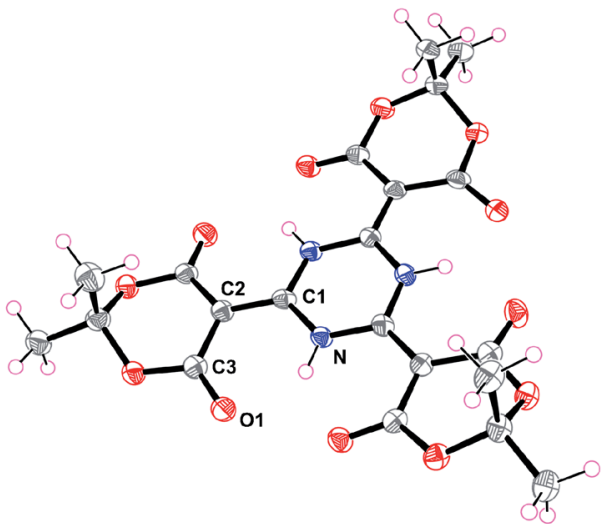

(b)

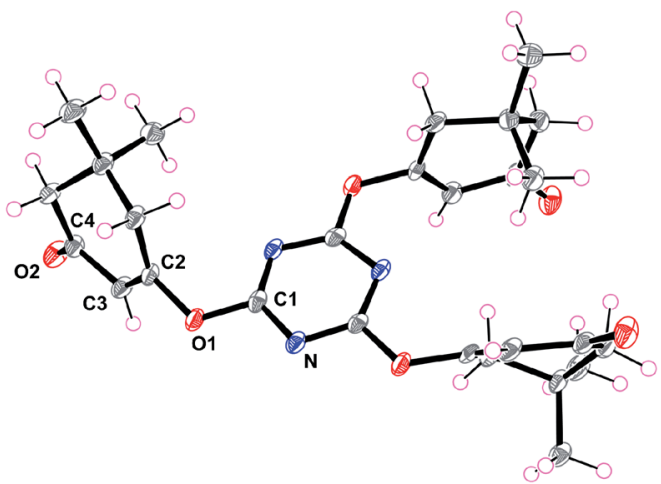

Fig. 1 X-ray crystal structures of (a) $3 a$ and (b) 4c. Thermal ellipsoids are set at $50 \%$ probability levels.

signals in the ratio of $2: 2: 2: 1$, where three signals $\left(\mathrm{H}^{\mathrm{b}}, \mathrm{H}^{\mathrm{c}}\right.$, and $\left.\mathrm{H}^{\mathrm{d}}\right)$ were located in the aliphatic region and one signal $\left(\mathrm{H}^{\mathrm{a}}\right)$ appeared in the olefinic region. The ${ }^{13} \mathrm{C}$ NMR spectrum (Fig. S10 $\left.{ }^{\dagger}\right)$ showed seven signals: three aliphatic $\left(\mathrm{C}^{5}, \mathrm{C}^{6}\right.$, and $\left.\mathrm{C}^{7}\right)$, two olefinic $\left(\mathrm{C}^{2}, \mathrm{C}^{3}\right)$, one aromatic $\left(\mathrm{C}^{1}\right)$, and one carbonyl $\left(\mathrm{C}^{4}\right)$. Dimedone (5,5-dimethyl-1,3-cyclohexanedione, 2c) gave results similar to those of $\mathbf{2 b}$. The crystal structure of $\mathbf{4 c}$ (Fig. 1b) revealed its authentic 1,3,5-triazine core with $\mathrm{N}-\mathrm{C}^{1}$ distances of 1.322(2)-1.333(2) $\AA$, as well as $\mathrm{N}-\mathrm{C} 1-\mathrm{N}$ and $\mathrm{C} 1-\mathrm{N}-\mathrm{C} 1$ bond angles of 127.5(2)-128.4(2) and 111.4(2)-112.2(2) ${ }^{\circ}$, respectively. ${ }^{13}$ Evident enol-enone moieties were also observed with the following bond distances: C1-O1, 1.342(2)-1.357(2); O1-C2, 1.410(3)-1.416(2); C2-C3, 1.309(3)-1.332(3); C3-C4, 1.463(3)1.477(3); and C4-O2 1.214(3)-1.228(3) A. No related condensation reactions occurred when acyclic $\beta$-dicarbonyls, such as acetylacetone $\left(\mathrm{R}=\mathrm{CH}_{3}\right)$, dibenzoylmethane $(\mathrm{R}=\mathrm{Ph})$, diethyl malonate $(\mathrm{R}=\mathrm{OEt})$, and hexafluoroacetylacetone $\left(\mathrm{R}=\mathrm{CF}_{3}\right)$, were used. These observations suggested that $\mathbf{2 a}$ may have several favourable factors contributing to its reaction with cyanuric acid: (1) a highly acidic active methylene, ${ }^{\mathbf{1 4}}$ (2) reduced steric hindrance due to its cyclic structure, and (3) low contribution from the enol form. Interestingly, these reactions did not proceed in the presence of tetrahydrofuran.

Next, we attempted to utilise sodium hydride as the base and found that only reactions in refluxing toluene provided good outcomes (Scheme 2). This procedure could address solid substrates that did not appear in a previous report. ${ }^{9}$ The

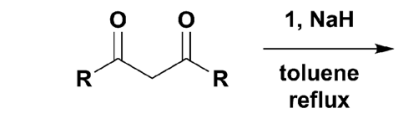

2b: $\mathrm{R}, \mathrm{R}=\mathrm{CH}_{2} \mathrm{CH}_{2} \mathrm{CH}_{2}$

2c: $\mathrm{R}, \mathrm{R}=\mathrm{CH}_{2} \mathrm{C}\left(\mathrm{CH}_{3}\right)_{2} \mathrm{CH}_{2}$

2d: $\mathrm{R}=\mathrm{OCH}_{2} \mathrm{CH}_{3}$

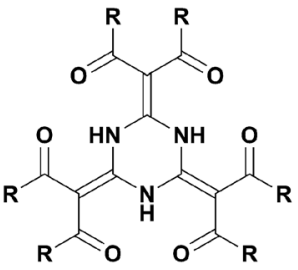

3b: $\mathrm{R}, \mathrm{R}=\mathrm{CH}_{2} \mathrm{CH}_{2} \mathrm{CH}_{2}$ 3c: $\mathrm{R}, \mathrm{R}=\mathrm{CH}_{2} \mathrm{C}\left(\mathrm{CH}_{3}\right)_{2} \mathrm{CH}_{2}$ 3d: $\mathrm{R}=\mathrm{OCH}_{2} \mathrm{CH}_{3}$

Scheme 2 Nucleophilic substitution of $\beta$-dicarbonyls $(2 b-d)$ onto cyanuric acid with sodium hydride in toluene under reflux.

suspensions gradually turned red, probably due to the sodium salts of the tri-conjugate intermediate. These precipitates containing excess sodium hydride were filtered out, purified by acidic aqueous treatment, and then recrystallised. This method could even be applied to weakly acidic and/or acyclic $\beta$-dicarbonyls that gave products $\mathbf{3 b}, \mathbf{3 c}$, and $\mathbf{3 d}$ (identical to a previously fabricated product ${ }^{9}$ ), whose NMR spectral trends were consistent with those of 3a. To our delight, the crystal structures of $\mathbf{3 b}$ and $\mathbf{3} \mathbf{c}$ showed slight yet significant differences from $\mathbf{3 a}$ regarding their bond lengths, which were caused by the electronic effects of substructures embedded at the carbonyl ends of 3b and 3c (Fig. S20 and S21†). These observations suggest that a potentially promising resonance hybrid involving proton transfers amongst the multi-hydrogen bonding entities could be fabricated and controlled by the attached functionalities (Chart S1a $\dagger$ ).

UV-visible absorption spectra of $\mathbf{3 a - d , ~} \mathbf{4 b}$, and $\mathbf{4 c}$ are shown in Fig. 2. The absorption bands of 3a appeared at $319-333 \mathrm{~nm}$, and 3d, belonging to the same ester family as $\mathbf{3 a}$, also had an illdefined absorption band at $317 \mathrm{~nm}$. The wave shapes of $\mathbf{3 b}$ and 3c were similar to one another but were in sharp contrast to those of 3a and 3d, displaying twin maxima at 348-362 and 346$361 \mathrm{~nm}$, respectively. Interestingly, they were accompanied by relatively intense bands at 236 and $238 \mathrm{~nm}$, respectively, and similar absorptions were also observed in the UV-vis spectra of 4b and 4c. As a preliminary speculation, the absorption band in

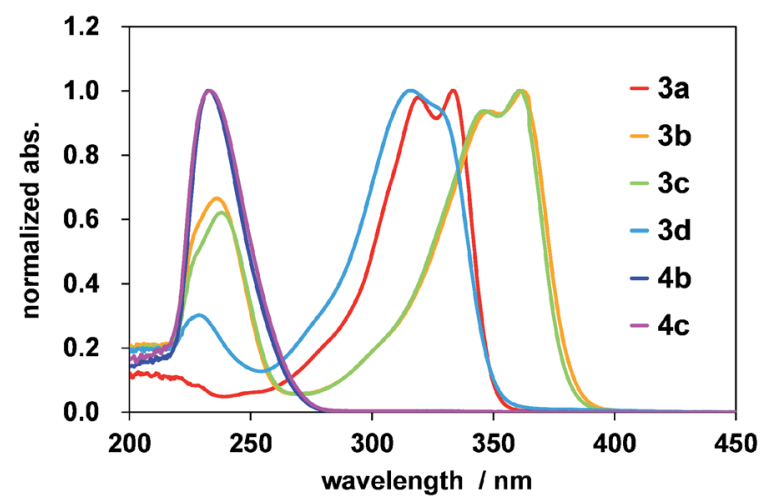

Fig. 2 UV-visible absorption spectra of the synthesised products in dichloromethane. 
the high-energy region was assigned to the $\pi-\pi^{*}$ transition of an independent $\alpha, \beta$-unsaturated carbonyl (enone) moiety, ${ }^{15}$ provided as a result of tautomerism and resonance (Chart $\mathrm{S} 1 \mathrm{~b} \dagger)$. In this context, such differences between $\mathbf{3 a} / \mathbf{3 d}$ and $\mathbf{3 b} / \mathbf{3 c}$ may be ascribed to the peripheral attachments of $\mathbf{3 b}$ and $\mathbf{3 c}$.

In summary, we demonstrated synthetic protocols for reacting $\beta$-dicarbonyls with 1,3,5-triazine, where subsequent tautomerism gave intramolecular multi-hydrogen bonding structures. These AHB systems were fully characterised by spectroscopic analyses and X-ray crystallography. These scaffolds overcame aromatic stabilisation and potentially adopted resonance hybrid structures that involved proton transfers. This provided molecules with excellent delocalised electronic networks upon optimising their peripheral substructures. We expect that this work will be reinforced by future theoretical investigations and other instrumental examinations, where a novel, molecular motif replacing polyaromatic hydrocarbons could be discovered.

\section{Conflicts of interest}

There are no conflicts to declare.

\section{Acknowledgements}

This work was supported by JSPS KAKENHI (Grant number 18K05082), and M. S. acknowledges the Electric Technology Research Foundation of Chugoku and the Tokuyama Science Foundation for financial support. We also thank Prof. Atsuhiro Osuka and Dr Takayuki Tanaka (Kyoto University) for their help with the X-ray measurements.

\section{Notes and references}

1 (a) B. Kuhn, P. Mohr and M. Stahl, J. Med. Chem., 2010, 53, 2601; (b) S. Scheiner, Molecules, 2017, 22, 1521; (c) G. Sánchez, Molecules, 2019, 24, 2858; (d) G. Caron, J. Kihlberg and G. Ermondi, Med. Res. Rev., 2019, 39, 17071729. and the references therein.

2 (a) Y. Tanaka, J.-Y. Shin and A. Osuka, Eur. J. Org. Chem., 2008, 1341-1349; (b) Y.-S. Xie, K. Yamaguchi, M. Toganoh, H. Uno, M. Suzuki, S. Mori, S. Saito, A. Osuka and H. Furuta, Angew. Chem., Int. Ed., 2009, 48, 5496-5499; (c) T. Soya, W. Kim, D. Kim and A. Osuka, Chem.-Eur. J., 2015, 21, 8341-8346; (d) C. Li, K. Zhang, M. Ishida, Q. Li, K. Shimomura, G. Baryshnikov, X. Li, M. Savage, X.-Y. Wu, S. Yang, H. Furuta and Y. Xie, Chem. Sci., 2020, 11, 27902795.

3 (a) G. J. Woolfe, M. Melzig, S. Schneider and F. C. Dorr, Chem. Phys., 1983, 77, 213-221; (b) S. Tobita, M. Yamamoto, N. Kurahayashi, R. Tsukagoshi, Y. Nakamura and H. Shizuka, J. Phys. Chem. A, 1998, 102, 5206-5214; (c) V. S. Padalkar and S. Seki, Chem. Soc. Rev., 2016, 45, 169-202.
4 (a) C.-Y. Peng, J.-Y. Shen, Y.-T. Chen, P.-J. Wu, W.-Y. Hung, W.-P. Hu and P.-T. Chou, J. Am. Chem. Soc., 2015, 137, 14349-14357; (b) Y.-T. Chen, P.-J. Wu, C.-Y. Peng, J.-Y. Shen, C.-C. Tsai, W.-P. Hu and P.-T. Chou, Phys. Chem. Chem. Phys., 2017, 19, 28641-28646; (c) M. Mamada, K. Inada, T. Komino, W. J. Potscavage Jr, H. Nakanotani and C. Adachi, ACS Cent. Sci., 2017, 3, 769-777.

5 (a) W. Y. Cha, T. Soya, T. Tanaka, H. Mori, Y. Hong, S. Lee, K. H. Park, A. Osuka and D. Kim, Chem. Commun., 2016, 52, 6076-6078; (b) T. Soya, H. Mori, Y. Hong, Y. H. Koo, D. Kim and A. Osuka, Angew. Chem., Int. Ed., 2017, 56, 3232-3236; (c) M. Umetani, J. Kim, T. Tanaka, D. Kim and A. Osuka, Chem. Commun., 2019, 55, 10547-10550.

6 (a) M. Stępień, L. Latos-Grażyński, N. Sprutta, P. Chwalisz and L. Szterenberg, Angew. Chem., Int. Ed., 2007, 46, 78697873; (b) J. Sankar, S. Mori, S. Saito, H. Rath, M. Suzuki, Y. Inokuma, H. Shinokubo, K. S. Kim, Z. S. Yoon, J.-Y. Shin, J. M. Lim, Y. Matsuzaki, O. Matsushita, A. Muranaka, N. Kobayashi, D. Kim and A. Osuka, J. Am. Chem. Soc., 2008, 130, 13568-13579; (c) T. Soya, H. Mori and A. Osuka, Angew. Chem., Int. Ed., 2018, 57, 15882-15886.

7 D. P. Fairlie, T. C. Woon, W. A. Wickramasinghe and A. C. Willis, Inorg. Chem., 1994, 33, 6425-6428.

8 (a) H.-J. Schulz, J. Liebscher, P. Luger, M. Quian and J. Mulzer, J. Heterocycl. Chem., 1992, 29, 1125-1132; (b) P. Gilli, V. Bertolasi, V. Ferretti and G. Gilli, J. Am. Chem. Soc., 2000, 122, 10405-10417.

9 Theoretical considerations of peripheral hydrogen bonding of aromatic rings were reported. (a) D. Rusinska-Roszak, Molecules, 2017, 22, 481; (b) I. V. Omelchenko, O. V. Shishkin, P. Dopieralski and Z. Latajka, J. Phys. Chem. A, 2019, 123, 2244-2251.

10 G. M. Vakhatova and L. N. Yakhontov, Chem. Heterocycl. Compd., 1980, 16, 433-436.

11 (a) C. A. M. Afonso, N. M. T. Lourenço and A. d. A. Rosatella, Molecules, 2006, 11, 81; (b) A. Chouai and E. E. Simanek, J. Org. Chem., 2008, 73, 2357-2366; (c) K. Yamada, H. Fujita and M. Kunishima, Org. Lett., 2012, 14, 5026-5029; (d) M. N. Kopylovich, K. T. Mahmudov, M. Haukkac and A. J. L. Pombeiro, New J. Chem., 2014, 38, 495-498; (e) N. Iranpoor and F. Panahi, Org. Lett., 2015, 17, 214-217; (f) C. H. Lin, Y. C. Chou, M. W. Wang and R. J. Jeng, $R S C$ Adv., 2016, 6, 17539-17545.

12 Partially similar crystallographic considerations were stated. N. Kuhn, A. Al-Sheikh and M. Steimann, Z. Naturforsch., 2003, 58b, 381-384.

13 P. J. Wheatley, Acta Crystallogr., 1955, 8, 224-226.

14 (a) H. McNab, Chem. Soc. Rev., 1978, 7, 345-358; (b) S. Nakamura, H. Hirao and T. Ohwada, J. Org. Chem., 2004, 69, 4309-4316.

15 R. B. Woodward, J. Am. Chem. Soc., 1941, 63, 1123-1126. 